\title{
A potencialidade das redes sociais na promoção de destinos turísticos: 0 caso de Tenerife
}

\section{Social Media as an opportunity for tourism destinations: The case of Tenerife}

\author{
Susana Wichels \\ Faculdade de Letras da Universidade de Coimbra, Portugal \\ susanaw@sapo.pt
}

\begin{abstract}
Resumo
As redes sociais, poderosas plataformas de relacionamento, captação e fidelização de clientes, nomeadamente o TripAdvisor, o Facebook e o Instagram ou a Blogosfera, estão a influenciar novos comportamentos do consumidor, obrigando a novas práticas em comunicação turística. Frente a esta realidade, as estratégias e ferramentas de comunicação e marketing tradicionais dos destinos turísticos mostram-se menos efetivas e a mudança envolve não só o como e quando se comunica, mas também o quê. Neste artigo analisamos, enquanto estudo de caso, a estratégia de comunicação e redes sociais de Tenerife. Como estará a reagir um dos destinos mais consolidados do mundo, à mudança de paradigma em comunicação turística?
\end{abstract}

Palavras-chave: Comunicação de destino turístico; turismo de Tenerife; redes sociais; turismo 2.0; estratégia de comunicação online em turismo; Espanha.

\begin{abstract}
Social media are powerful platforms for relating to, capturing and establishing loyalty relationships with clients. Platforms such as TripAdvisor, Facebook, Instagram or the Blogosphere are influencing new consumer behaviours and obligating new practices in tourism communication. In the light of this, the traditional marketing and communication tools and strategies of tourism destinations are becoming less effective, and the change involves not only how and when but also what to communicate. In this paper, we analyse the communication and social media strategy of Tenerife as a case study. How is one of the most consolidated tourism destinations in the world reacting to the changes in the tourism communication paradigm?
\end{abstract}

Keywords: Communication of tourist destination; Tenerife tourism; social media; tourism 2.0; online tourism communication strategy; Spain.

\section{Introdução}

A importância estratégica do setor turístico no mundo, e em especial para Portugal, motiva a necessidade de aprofundar e sistematizar estudos específicos na área da comunicação turística para tornar o turismo português mais competitivo frente a outros mercados. Neste artigo propomos examinar as estratégias e práticas de comunicação de um destino turístico de êxito, Tenerife - Espanha, para daí se extraírem as best practices que possam vir a ser aplicadas nas nossas regiões turísticas. O presente trabalho, que tem por objetivo a análise da estratégia de comunicação turística de Tenerife, está estruturado da seguinte forma: iniciamos com um breve enquadramento teórico sobre a importância da comunicação em

Dos Algarves: A Multidisciplinary e-Journal, $32-2018$.

ISBN 2182-5580 @ ESGHT - University of the Algarve, Portugal.

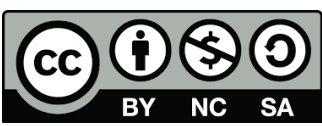

To cite this article: Wichels, S. (2018). Comunicação turística desafios e tendências na contemporaneidade. O caso deTenerife. Dos Algarves: A Multidisciplinary e-Journal, 32, 88-106. doi: 10.18089/DAMeJ.2018.32.6 
turismo e a alteração paradigmática da comunicação 2.0 e 3.0 provocada pelos avanços e usos das novas tecnologias de informação e comunicação; depois passamos à análise da estratégia de comunicação de Tenerife, utilizando a metodologia de investigação de estudo de caso. O nosso objetivo é provocar uma reflexão sobre a comunicação turística, apresentando um exemplo de best practices comunicacionais de um destino turístico de êxito, aportando assim conhecimentos que fortaleçam um dos setores mais importantes para o futuro de Portugal.

\section{Contextualização teórica}

Encontramo-nos num momento de mudança no processo como o turista se informa, como é influenciado e como decide reservar o seu próximo destino de lazer. Existem hoje múltiplas fontes de informação e novos canais disponíveis, o indivíduo envolve-se de forma proativa no processo da procura, seleção, decisão, reserva e recomendação do destino, dos meios de transporte, do alojamento e das restantes atividades e experiências de lazer e ócio.

Regista-se uma mudança no hábito de compra dos consumidores da "indústria" turística, a comercialização online tem maior preponderância que a offline, a decisão de compra dos consumidores turísticos online é influenciada pelas valorizações e comentários feitos por outros consumidores. O poder de persuasão da publicidade e do publicity em meios de comunicação tradicionais é cada vez menos efetiva. Estamos perante um novo modelo comunicacional poliédrico que assenta num mix de fontes online e offline onde os canais com maior poder de influência são os comentários realizados online por líderes de opinião de pequenos grupos, ou seja, a comunicação interpessoal em redes sociais como o Facebook e o Instagram, blogues de viagem e aplicações do tipo TripAdvisor, seguido de recomendações offline de amigos e familiares; e cada vez com menos relevância os canais tradicionais.

Em concreto, em relação ao novo modelo comunicacional poliédrico que assenta no mix de fontes online e offline, verifica-se que, dependendo da fase e do produto de compra, o turista nem sempre é influenciado da mesma forma pela mesma fonte (Fotis, Buhalis \& Rossides, 2012). Neste modelo, os fluxos de influência das fontes de comunicação variam segundo o momento do consumo. Na fase de pré-viagem, na qual é necessário decidir o destino, o alojamento e o transporte, encontramos a supremacia das fontes online, nomeadamente a consulta de páginas Web, blogues de viagem e as recomendações de conhecidos e pequenos líderes de grupos de opinião através das redes sociais. Também relevantes, mas com menos influência, são as fontes offline, concretamente a comunicação interpessoal, ou seja, a partilha de informações com amigos, familiares, as recomendações realizadas por especialistas (agências de viagem ou empresas fornecedoras de experiências turísticas) e os folhetos turísticos. Com cada vez menos influência, aparecem os meios de comunicação tradicionais de mainstream (jornais, revistas, televisão e rádio).

Quando o turista já se encontra no destino e precisa decidir sobre quais as experiências para ocupar o seu tempo livre, então a relevância das fontes de informação é completamente diferente e consiste em: receções de estabelecimentos hoteleiros onde recebem conselhos dos rececionistas e informação através de folhetos; postos de turismo onde auferem de conselhos dos especialistas e as narrativas turísticas oferecidas pelos folhetos; meios de 
comunicação especializados e oficiais, em concreto as agendas de eventos, revistas e o canal de televisão sobre o destino oferecido nos quartos de hotel.

Portanto, o canal online, nomeadamente as páginas Web e a comunicação interpessoal permitida pelas redes sociais, destacam-se como a fonte de informação mais influente em país de origem e, em concreto, nos momentos pré-consumo e pós-consumo (Fotis et al., 2012). O canal offline aparece como a fonte de informação em destino mais relevante para a divulgação da região turística e da variada oferta de experiências durante o momento do consumo.

As questões que se levantam são: Como é possível influenciar o comportamento do turista perante a propagação de canais online e offline e de emissores-recetores em qualquer ponto da cadeia comunicacional? e que tipo de práticas e estratégias de comunicação se devem pôr em marcha para encarar este novo contexto?

Se qualquer processo de comunicação envolve uma tensão, com a crescente mudança em comunicação turística as tensões multiplicam-se, num reflexo contínuo de canais, mensagens e ruído. A Internet faz da procura e da planificação da viagem, uma tarefa cómoda e ágil. Hoje podemos visitar virtualmente destinos, ver vídeos online, fotografias e conhecer as opiniões de turistas que já visitaram o mesmo lugar, ou que estão no momento a visitar e a emitir as suas opiniões através das redes sociais quase em live-stream.

As novas tecnologias de informação, em concreto as aplicações Web 2.0, redes sociais ou social media, afirmam-se como poderosas plataformas de relacionamento, captação e fidelização de clientes, e são responsáveis pela mudança de paradigma nas estratégias de comunicação no setor turístico. O aumento de utilizadores das aplicações Web 2.0 tem gerado um fluxo de comentários e opiniões online capazes de influenciar as vendas de vários produtos. As aplicações que mais estão a influenciar o e-turismo (Buhalis, 2003), para além das redes sociais Facebook, Instagram e Twitter que já dispensam apresentações, são o TripAdvisor (Miguéns, Baggio \& Costa, 2008; Wichels, 2014b), Expedia, Rumbo ou Booking. São empresas surgidas no contexto da Web 2.0, mediadoras de serviços que obtêm a informação necessária para facilitar novos processos de inovação a partir da investigação em mercados específicos com painéis de consumidores. Estas redes específicas de turismo são capazes de criar e manter redes de consumidores, sistemas de relação de feedback com os segmentos de mercado do seu interesse. Igualmente, as redes sociais vieram potenciar o surgimento de novos atores, os digital influencers (Uzunoglu \& Misci Kip, 2014; Tratt, 2014; Tseng, Wu, Morrison, Zhang \& Chen, 2015) e obrigam a novas práticas em comunicação turística (Hays, Page \& Buhalis, 2012; Kietzmann, Hermkens, McCarthy \& Silvestre, 2011; Sigala \& Gretzel, 2018).

No turismo 2.0, os viajantes adquiriram maior protagonismo devido aos mecanismos de participação direta oferecida pelas plataformas digitais (Anderson, Hepworth, Lecturer, Kelly, Manager \& Phipps, 2007). O usuário passou de consumidor a exercer a dupla função de consumidor e produtor, o prosumer (Toffler \& Toffler, 2006), a interatuar, a criar os seus próprios conteúdos e os seus comentários ganharam força e poder na cadeia de produção e distribuição.

Fernández (2012: 289) refere que foi com a adoção de blogues, wikis e redes sociais, que a Internet e a comunicação em turismo entraram na era da Web 2.0. Porém, com a crescente utilização dos smartphones que promovem a partilha da experiência do utilizador em todas as fases da viagem, influenciando, indubitavelmente, a decisão de outros, alguns autores 
falam já do turismo 3.0 (Bastian, Dreyer \& Gross, 2009; Urry \& Larsen, 2011; Dunn, 2015; Sigala \& Gretzel, 2018). A comunicação em turismo, nesta fase, impulsionada por um salto tecnológico (a inclusão de sistemas de georreferenciação, câmaras e Internet nos smartphones) carateriza-se por ser ubíqua, em tempo real, sem gatekeepers ou filtros, e com informação georreferencial partilhável e reproduzível (Wong, Law \& Li, 2017; Lalicic \& Dickinger, 2017).

A Web 3.0 refere-se, em geral, à transmissão de dados sem ser necessário a utilização de navegadores, realizando-se através de aplicações, e à unificação das linguagens de programação de forma a criar-se uma "Web semântica" onde cada programa e aplicação recolhe informação do utilizador, conseguindo uma navegação mais orgânica. Esta fase vai mais além de oferecer informação e de permitir a comunicação entre pessoas, e representa a terceira geração de comunidades e serviços que aproveita o efeito exponencial de rede, de modo que, quanto mais as aplicações são utilizadas, mais ricas se tornam, criando um círculo informativo denso, complexo e altamente atrativo. A experiência do utilizador é a base para o processo de construção da inteligência coletiva, produzida a partir de uma arquitetura social e participativa (Jandt, 2010; Kotler, Kartajaya \& Setiawan, 2010).

O turismo 3.0 traduz-se, por exemplo, em todas as superfícies em destino (aeroporto, restaurante, local histórico, entre outros) em que se possa ler um código $Q R$, vídeos e fotografias em base de dados com links reproduzíveis em smartphones em diversos formatos e na facilidade através da qual o utilizador é capaz de criar, enriquecer e partilhar esses mesmos conteúdos através de diversas aplicações.

Ora, se a comunicação em turismo é um processo complexo, omnipresente, bidirecional, simétrico e absolutamente necessário para criar, manter ou corrigir a imagem de um destino, a empresa ou marca turística terá então, um papel crucial na fidelização ou no despertar do interesse do turista, no influenciar do processo de escolha e em manter viva a recordação das experiências sentidas de forma a provocar a recomendação e a volta.

Uma das funções principais da comunicação é seduzir o turista, convidá-lo a lugares paradisíacos e a espaços contrários ao seu mundo quotidiano. Através da comunicação, os destinos procuram destacar-se dos seus concorrentes sugerindo experiências autênticas e narrando estórias de povos, lugares e culturas que seduzam pela diferença, exotismo, tipicidade ou afabilidade. Comunica-se para persuadir, para conseguir um determinado efeito.

A estratégia em comunicação turística terá sempre como objetivo final, influenciar ou persuadir o comportamento dos potenciais turistas para que visitem e contribuam com receitas para o crescimento económico do destino. Pretende-se igualmente influenciar o comportamento dos diferentes stakeholders, sejam eles os públicos internos / atores étnicoslocais ou as empresas colaboradoras e fornecedoras de experiências. Esta comunicação envolve um jogo de forças, o discurso a favor das assimetrias de poder, e a supremacia de um destino em relação aos seus competidores regionais, nacionais e internacionais.

Entendendo o turismo como um fenómeno sociológico que corresponde à satisfação de necessidades de evasão, emoção, crescimento pessoal ou reconhecimento social, a comunicação turística deve definir estratégias assentes em modelos experienciais (Schmitt, 2010) e fornecer experiências que satisfaçam as necessidades e o desejo dos turistas. De acordo com Zarantonello, Jedidi e Schmitt (2013), Sharpley e Stone (2011) e Wichels (2014a), a comunicação experiencial é a que tem demonstrado melhores resultados como fenómeno 
persuasor do consumidor. A "plataforma comunicativa experiencial” proposta por Schmitt (2010: 89) é multidimensional, multissensorial e altamente dinâmica.

O turista parece ter uma certa dificuldade em tomar decisões baseadas somente em aspetos racionais. Muitas vezes são os argumentos emocionais que despoletam a ação ou que fazem a balança da decisão pender mais para um lado ou para o outro. Dito isto, a comunicação turística de um destino deve adotar elementos argumentativos racionais, mas igualmente argumentos emotivos que estimulem sensações. No nosso estudo, examinámos o caso do destino turístico espanhol, Tenerife - Ilhas Canárias - para perceber, através da análise da estratégia de comunicação turística, como utilizam as redes sociais para posicionar e fortalecer a imagem do destino e aplicam de forma empírica os conceitos de comunicação experiencial proposto por Schmitt (2010) e Zarantonello et al. (2013).

\section{Metodologia}

A análise da estratégia de comunicação turística do destino Tenerife seguiu a metodologia de recolha de dados e evidências de construção de estudos de caso em ciências sociais de Robert K. Yin (2001), enquanto método de pesquisa para a investigação de inferências válidas a partir de eventos que se encontram fora dos limites do laboratório, ao mesmo tempo que se mantêm os objetivos do conhecimento científico (Yin, 2001).

Como se trata de um estudo de caso único, optámos por uma abordagem holística (idem ibidem), uma metodologia mista que combina técnicas de análise qualitativa e quantitativa. Reunimos diversos documentos estatísticos e de planificação estratégica, bem como material de promoção turística offline e online de forma a colecionar o maior número de narrativas turísticas possíveis e poder apresentar uma fotografia da estratégia de comunicação turística de Tenerife durante o período de 2012-2013.

Realizámos entrevistas semiestruturadas ao diretor de marketing e comunicação de Turismo de Tenerife, Javier Pérez, e à diretora da Factoría de Innovación Turística de Tenerife, Carmen de Miguel, enquanto especialistas de elite (Ribeiro, 2013) e responsáveis pela criação e implementação do plano da estratégia de comunicação do destino. Analisámos material estatístico publicado (Turismo de Tenerife, 2012, 2013a, 2013b, 2014), folhetos e documentos oficiais relacionados com a estratégia turística recolhidos no Governo Autónomo de Tenerife (Cabildo) e Turismo de Tenerife. Analisámos os resultados estatísticos de 11000 inquéritos Encuesta de Turismo Receptivo e de 5000 inquéritos da Encuesta de Imagen y Competitividad relativos a 2012 e 2013. Observámos, através de uma metodologia qualitativa, várias peças de comunicação turística, nomeadamente folhetos físicos, outdoors, campanhas online, as páginas Web de Turismo de Tenerife e as correspondentes páginas em redes sociais (ver Anexos 2, 3 e 4).

\section{A estratégia de comunicação turística de Tenerife}

Tenerife, "a ilha da eterna primavera”, pertence ao arquipélago espanhol das Ilhas Canárias. As Canárias têm um regime de governo autónomo regional, o Gubierno de la Islas Canárias, que está dividido administrativamente em duas províncias, Las Palmas de Gran Canária e Tenerife, e é responsável por treze áreas de governo, sendo o turismo uma delas. Para 
encarregar-se diretamente de todas as gestões relacionadas com o turismo, foi criada uma entidade pública de gestão de destino: Turismo de Tenerife, S.A.

A estratégia entende-se, em comunicação, como a planificação de um percurso composto por etapas e ações a implementar num determinado momento, ou seja, o conjunto de linhas orientadoras e ações planificadas de forma sistemática e enquadradas numa matriz temporal, de forma a atingirem-se metas e objetivos previamente delineados. A estratégia de comunicação segundo Horsle (2005) materializa-se em instrumentos e resultados chave em áreas prioritárias e contribui para que um governo ou uma organização atinja os efeitos desejados sobre os seus utilizadores e a comunidade em geral. A estratégia de comunicação turística de um destino não constitui um monólito, pelo contrário, deve ir desenhando-se e atualizando-se conforme os resultados obtidos e as mudanças registadas nos mercados.

No entanto, cabe recordar que a estratégia de comunicação de uma empresa, organização ou de um destino turístico não é facilmente medida a curto ou a médio prazo. Não estamos em laboratório, portanto não é possível isolar o objeto de estudo, e resta-nos fazer uma delimitação temporal, assumindo que esta poderá estar influenciada por acontecimentos anteriores ou posteriores e inserida num contexto mais abrangente. Porém, não podemos falar da estratégia de Tenerife sem inseri-la no contexto das Ilhas Canárias. A construção de uma marca e da personalidade de um destino demora anos a construir e é fruto da interação entre estratégias de 216 atuação públicas e privadas.

Em certos momentos é preciso recuar às estratégias implementadas em anos anteriores, para poder interpretar os resultados de hoje. A informação quantitativa é baseada na análise dos inquéritos aos turistas que visitaram a ilha em 2012 e 2013, e deve ser vista como uma medição (das muitas possíveis) das campanhas e da estratégia de comunicação turística.

A estratégia de comunicação de um destino não pode ser vista como uma pauta inflexível. O seu objetivo é guiar a administração pública, as empresas e todos os stakeholders envolvidos no setor turístico, e deve ser gerida de forma flexível para se adaptar às mudanças constantes dos contextos local, regional, nacional e internacional. Por conseguinte, são vários os países e destinos turísticos que estabelecem objetivos com um horizonte de três, ou de cinco anos e, em várias ocasiões, apresentam revisões e atualizações periódicas ao rumo marcado inicialmente.

\section{Revisão do modelo turístico}

Em 2011, devido à mudança do paradigma da comunicação online (2.0), revisaram-se algumas das linhas de atuação inicialmente propostas e foi criado o documento de Renovação da Estratégia Turística de Tenerife, 2012-2015. Esta atualização resultou de um processo de escuta e colaboração entre os diferentes stakeholders turísticos, públicos e privados, dos seus objetivos e visões.

Propôs-se uma revisão do modelo turístico e uma gestão proactiva do destino para superar os desafios competitivos dos mercados turísticos internacionais. As linhas de atuação em comunicação e marketing propostas têm por objetivo "fazer mais, com menos", isto é, oferecer melhores resultados com menos recursos num contexto cada vez mais complexo. O destino turístico é entendido como um todo global, que necessita de respostas integrais desde a promoção à revitalização, da atenção ao cliente, passando pelas questões 
da acessibilidade, conectividade, desenvolvimento tecnológico, inovação e aposta por novas áreas do conhecimento.

O novo modelo encara o destino turístico como um conceito abrangente que enquadra não só o espaço físico, económico e social, mas também o conjunto de experiências, produtos e serviços turísticos (Turismo de Tenerife, 2012). A fórmula proposta pelo Turismo de Tenerife para manter o seu estatuto de destino turístico de referência reside na gestão integral dos diferentes recursos, produtos e serviços turísticos de forma a oferecer uma experiência completa e memorável. É uma visão estratégica orientada para a excelência e uma estrutura de gestão inspirada num modelo turístico holístico. Acreditam que é necessário estimular a comunicação constante, positiva, fluída e eficaz entre os multistakeholders, incidindo em especial no modelo de comunicação com fluxos bilaterais e multicanal entre players públicos e privados, em suma: "lograr, con la implicación y participación de todos, una gestión basada en la responsabilidad compartida del destino" (Turismo de Tenerife, 2012: 5).

Para além disso, marcaram-se exigentes critérios de qualidade para serem seguidos tanto pela gestão pública como pela privada. A estratégia de comunicação turística de Tenerife tem por objetivo assegurar que todos os multistakeholders estejam perfeitamente informados, envolvidos e sincronizados na persecução do objetivo comum: a excelência do destino.

A organização de gestão do destino pretende alcançar o desenvolvimento global do espaço e dos produtos melhorando o posicionamento de Tenerife em relação à concorrência através de uma organização mais estruturada e eficiente da oferta de produtos e serviços. Igualmente, realiza esforços para estimular fluxos comunicativos profícuos entre as administrações públicas, local, regional e nacional e os diferentes setores económicos que influenciam direta ou indiretamente no turismo.

A estratégia recomenda optar por ferramentas de promoção eficazes e que ofereçam um retorno do investimento, em concreto pelas novas tecnologias, redes sociais e digital influencers como os blogues de viagem ou as revistas especializadas. Existe também o interesse em fomentar uma cultura de inovação e de investigação de forma a acompanhar os novos campos de conhecimento essenciais para a excelência do destino turístico. Esta linha de ação inclui a aposta pela profissionalização, formação e especialização do setor.

O novo modelo turístico vai mais além do que uma mudança nas narrativas turísticas ou nos argumentos promocionais em peças de comunicação, prevê gerar uma estratégia de negócio holística, que englobe os produtos, serviços e experiências dos turistas e igualmente da população residente, a quem, como elemento unificador do destino, o turismo deve trazer bem-estar, oportunidades e satisfação.

Considera-se essencial a dinamização do setor empresarial para estimular o desenvolvimento de novas experiências, produtos e atividades, e revitalizar segmentos tradicionais na ilha. O Turismo de Tenerife desenvolve ações para captar financiamento externo para desenvolver ou aperfeiçoar a qualidade da oferta turística e, ao mesmo tempo, realiza lobbying para que os quadros legislativos favoreçam a competitividade do setor e apoiem a simplificação administrativa dos processos e trâmites necessários ao desenvolvimento. 


\section{Tipologia de turista}

Antes de continuarmos a explorar, agora com maior detalhe, as ações desenvolvidas pela estratégia de comunicação de Turismo de Tenerife, importa traçar um quadro atual do setor e a tipologia do turista que visita este destino. Durante o ano de 2013, Tenerife recebeu 6.064.977 passageiros, dos quais 4.973.047 foram identificados como turistas alojados e com uma estância média de 7,7 dias. O número total de dormidas foi de 38.645.646, com um valor médio de $64,6 \%$ de ocupação anual. O turista que visita Tenerife apresenta uma idade média de 47,13 anos.

A tipologia familiar dos turistas que escolhem a ilha é composta por casais (59,0\%) e famílias com crianças (19,0\%). As nacionalidades que mais visitam Tenerife são a britânica, espanhola, alemã, escandinava (sueca, norueguesa e finlandesa), russa, holandesa, francesa, seguidas dos restantes mercados. Devido à multiplicidade de nacionalidades, o Turismo de Tenerife aposta pela diferenciação e eficácia da promoção turística através da personalização dos conteúdos promocionais segundo os segmentos de mercado estratégicos. Organizam e participam em eventos de interesse turístico nos países emissores e apoiam a indústria em ações de promoção exterior, entre outras linhas de ação.

Para aumentar a eficácia das ferramentas promocionais, diferenciar e revitalizar a imagem dos produtos e serviços turísticos representados nos diferentes mercados emissores, o Turismo de Tenerife pôs em marcha várias ações para reorientar as suas marcas de produto: Tenerife Select, Tenerife Golf, Tenerife Natural, Tenerife Convention Bureau (TCB) e Tenerife Film Commission. Realizaram igualmente a revisão dos conteúdos promocionais, alinhando-os com a nova estratégia de posicionamento. Procuraram apresentar a variedade de experiências oferecidas no destino, melhorar a eficácia dos canais de comunicação apostando nas novas tecnologias e desenvolver experiências que estejam de acordo com as caraterísticas, motivações e interesses dos mercados e nichos emissores de turistas. Para além disso, a aposta num produto com experiências diversificadas representa, não só, ter uma imagem mais forte nos mercados internacionais, mas também assegura uma economia de destino mais saudável.

Em 2013, o valor das receitas geradas no destino pelos turistas foi de 3.720 milhões de euros. Os turistas apresentaram uma despesa média de 1079€ e um gasto diário de 113,78€ por pessoa. Estes valores distribuem-se pelas diferentes atividades e experiências oferecidas. O nível médio das rendas familiares dos turistas foi de 52.676,16 euros anuais. Concretamente $42,6 \%$ dos turistas apresentam um rendimento familiar superior a 45 mil euros e observa-se que $25,3 \%$ tem um rendimento familiar superior a 66 mil euros. Os maiores níveis de rendimento familiar correspondem ao turismo escandinavo e os menores aos mercados espanhol e italiano.

Existe, portanto, um potencial económico para aumentar as receitas de turismo, em especial no que toca ao consumo de experiências e atividades. São precisamente as receitas geradas pelas experiências que mais contribuem para o valor total das receitas turísticas geradas em destino. O setor da restauração apresenta-se como o mais rentável, graças à elevada percentagem de turistas que desfrutam de experiências gastronómicas (77,3\%), e contribui com $32,5 \%$ do total de ingressos turísticos em destino. Realizar compras é a segunda atividade mais popular, registando $17,4 \%$ das receitas em destino, seguida da compra de comida (11,4\%). As excursões organizadas e os rent-a-car contribuem para as receitas do destino com 6,9\% e 6,7\% respetivamente. Em seguida situam-se as atividades desportivas, 
ócio noturno, despesas diversas fora do estabelecimento hoteleiro, ou tratamentos em spas, com percentagens de utilizadores que variam entre os 2,0\% e os 5,0\%. Em 2013, mais de $58,0 \%$ dos visitantes declararam ter desfrutado de alguma experiência durante a sua estada em Tenerife.

As experiências favoritas são as gastronómicas (77,0\%), visitas a parques temáticos (31,1\%), passeios a pé (15,7\%), avistamento de cetáceos (13,1\%), subida em Teleférico ao vulcão Teide (12,1\%), visitas a museus, concertos e exposições (6,7\%), tratamentos de saúde, spas e massagens $(6,0 \%)$, entre outras. Os lugares mais visitados da ilha são por esta ordem de importância: o vulcão Teide (Parque Nacional de las Cañadas), a cidade de Santa Cruz e a cidade de Puerto de la Cruz. La Laguna, cidade universitária e património mundial declarado pela Unesco também registou um aumento do número de visitantes.

Reconhecendo a necessidade de melhorar a formação sobre a diversidade da oferta tanto na origem como no destino, o Turismo de Tenerife organizou experience trainings e workshops. Adicionalmente, realizaram-se melhorias na comunicação que permite guiar a descoberta dos diferentes sítios e experiências, como mapas, sinalética urbana, e a atualização de conteúdos sobre as atividades através da inclusão de elementos de comunicação 3.0. como sinaléticas com códigos $Q R$, informações de georreferenciação e simulações de realidade aumentada. Para além disso, melhorou-se o acesso a aplicações que favoreçam a interatividade entre turistas, destino e stakeholders turísticos.

\section{Resultados empíricos}

A Internet, as redes sociais e as aplicações 2.0 foram incorporadas no plano de comunicação de Turismo de Tenerife como canal prioritário ao reconhecerem a crescente influência das novas tecnologias no processo de comunicação turística. De acordo com os resultados dos inquéritos, 79,8\% dos turistas que viajaram para Tenerife em 2012, utilizaram a Internet para procurar informação sobre o destino, a viagem, os serviços e produtos turísticos disponíveis (Turismo de Tenerife, 2012).

Mais de metade dos turistas (59,7\%) reservou ou contratou online algum dos serviços da sua viagem. Alguns turistas utilizaram a Internet apenas para realizar consultas sobre os serviços da viagem $(20,2 \%)$ e decidiram por outra forma de contratação. Apenas $18,3 \%$ confirmaram não ter utilizado a Internet na planificação, compra ou reserva da sua viagem. Mais de metade dos turistas (59,0\%) fizeram a contratação online do seu bilhete de avião e $42,9 \%$ do alojamento, percentagens com tendência altista se revisarmos os dados dos últimos anos. A contratação direta ou presencial foi de apenas 39,0\% para o voo e 38,0\% para o alojamento, percentagens que apresentam uma tendência decrescente (Turismo de Tenerife, 2012).

Estas tendências não se manifestam de igual forma para todos os mercados emissores, revelando talvez o grau de confiança e desenvolvimento dos países em relação à compra online. Os resultados dos inquéritos mostram que os mercados inglês e escandinavo têm especial preferência pela utilização dos portais Web dos operadores turísticos. O mercado irlandês, para além de utilizar os portais dos operadores turísticos, usa também as páginas Web corporativas. Já os mercados alemão, espanhol e o italiano preferem ainda realizar a contratação física, isto é, presencial, nas agências de viagem. Verifica-se, no entanto, se olharmos para os números dos últimos anos, um crescimento de utilização, nos mercados 
italiano e espanhol, das páginas Web corporativas das companhias aéreas. No mercado alemão, embora aumentem o número de websites que oferecem esse serviço, ainda existe uma contratação inferior à média. Os holandeses e belgas mantêm a sua histórica preferência pelas agências de viagem tradicionais, mas vão começando timidamente a incorporar nos seus hábitos de reserva o uso de portais de operadores turísticos e websites de companhias aéreas. $O$ mercado francês reparte a contratação tanto em agências de viagem, portais $e$ websites de companhias aéreas e alojamentos. O mercado russo, embora prefira a contratação direta, física, através dos operadores turísticos especializados começa, pouco a pouco, a despertar para a contratação online através das páginas Web dos operadores turísticos, companhias aéreas e websites dos estabelecimentos de alojamento.

Pelo exposto, embora existam ainda diferenças por nacionalidade em relação à forma da contratação da viagem, a maioria dos turistas, cerca de $80,0 \%$, utilizou a Internet como principal fonte de informação turística sobre a ilha, a viagem e as experiências em destino. Destes $80,0 \%, 59,7 \%$ comprou ou reservou os serviços da viagem online, e só um $20,2 \%$ utilizou a Internet apenas para consultar informação sobre os produtos, mas não chegou a efetivar as suas compras. Destaca-se ainda que $34,6 \%$ utilizou a Internet como meio de informação geral sobre o destino, mas não realizou a gestão online dos serviços da viagem.

Detetam-se ainda, por nacionalidade, variações no comportamento de planificação da viagem online. Os países escandinavos, os britânicos e os irlandeses são os que mais utilizam a Internet para adquirir os serviços da viagem. Estes mercados apresentam uma percentagem de compra e reserva online superior ao $68,0 \%$, no caso concreto dos noruegueses, dinamarqueses e holandeses chegam aos $80,0 \%$. Em todos os mercados verifica-se a tendência altista do crescimento do comportamento de compra ou reserva online nos últimos anos.

\section{Redes sociais}

Passamos agora a analisar em detalhe o uso das redes sociais, que parecem adquirir cada vez mais relevância como fonte de informação turística. Sessenta e dois por cento dos turistas declararam ser utilizadores habituais de redes sociais, uma subida $(+10,5 \%)$ em relação ao ano anterior. Ainda mais acentuado $(+18,0 \%)$ foi o crescimento registado em 2012 na utilização das redes sociais para fins de pesquisa e partilha de informação relacionada com as férias, viagens e estabelecimentos turísticos, para receber e dar conselhos, partilhar fotografias, experiências, escrever e ler opiniões e valorações e procurar ofertas. Cerca de $45,7 \%$ dos turistas declararam ter utilizado as redes sociais para esses fins.

Observam-se diferenças nos objetivos e na forma de uso das redes sociais para fins de informação turística. Em relação aos objetivos, 33,5\% dos turistas dão e recebem conselhos; $28,0 \%$ partilham fotografias; $27,0 \%$ partilham experiências e um $24,0 \%$ procuram ofertas. Em relação à forma de uso, as redes sociais parecem utilizar-se com maior intensidade antes da viagem $(38,2 \%)$. Durante a viagem a percentagem diminui $(16,5 \%)$ e a utilização volta a reativar-se depois da viagem (25,4\%) (Turismo de Tenerife, 2012 ).

Dos resultados dos inquéritos podemos concluir que o poder prescritor das redes sociais está a aumentar e que a sua utilização como fontes de informação sobre o destino turístico é cada vez mais importante. As redes sociais mais utilizadas pelos turistas foram: $45,0 \%$ Facebook, 27,0\% Youtube, 20,0\% TripAdvisor, 9,0\% Twitter, 3,0\% Tuenti. 
Os turistas continuam a utilizar os telemóveis quando estão de viagem, nomeadamente $33,8 \%$, mas o acesso à Internet através do dispositivo móvel é mais limitado, só $22,5 \%$ dos turistas acedem à Internet se houver um ponto de ligação wifi grátis ou têm contratada alguma tarifa plana (6,8\%). Depreende-se aqui a importância de melhorar as infraestruturas de acesso livre à Internet nos destinos turísticos, de forma a promover a partilha em redes sociais das experiências e fotografias em tempo real. Trata-se de aproveitar uma situação onde concorrem vários fatores que podem potenciar uma prescrição voluntária do destino: tempo, vontade de compartir e conteúdos novos e excitantes. Porque está de férias, o turista tem mais disponibilidade e tempo livre. Está fora do seu contexto "ordinário", tem histórias "extraordinárias" para contar e quer partilhá-las com o seu grupo de referência ou influência.

Recordemos que as férias podem ser a expressão de afirmação e de prestígio da pessoa já que "a escolha do destino e do alojamento, podem tornar-se um meio do indivíduo se valorizar no interior de um grupo" (Tocquer \& Zins, 1999: 93). O turismo é um definidor de estilos de vida "Se as pessoas não viajarem, elas perdem o status. A viagem é a marca do status" (Urry, 2001: 20). Portanto, os familiares, amigos e conhecidos que normalmente residem nos países emissores, ao receberem as narrativas turísticas, podem ser influenciados e transformar-se futuramente em potenciais visitantes. Conclui-se, assim, que dar a oportunidade ao turista de estar ligado à Internet é potenciá-lo como ator-prescritor voluntário do destino em tempo real.

\section{Promoção e comunicação online na estratégia de comunicação turística}

Reconhecendo a importância da comunicação online, Turismo de Tenerife planeou ações para melhorar a visibilidade do destino na Internet, aumentando a presença em websites de terceiros, blogues de viagem e em redes sociais. A estratégia de comunicação online integra um plano de relacionamento que interatua com os turistas durante os três momentos-chave do processo de consumo turístico: antes da viagem (Web, blogues de viagem e redes sociais), durante a viagem (ações em terminais móveis e uso de aplicações informativas sobre o destino) e após a viagem (estimulando a recomendação positiva em redes sociais, o reavivar das experiências e a vontade de voltar, através de ações de email-marketing e concursos).

Um dos objetivos da estratégia de promoção e comunicação online é tornar a Web oficial (webtenerife.com), como a Web de referência de informação turística sobre o destino no ciberespaço. O Turismo de Tenerife desenvolve continuamente ações para melhorar o desenho gráfico e os conteúdos deste portal. A Web oficial webtenerife.com teve, em 2013, 2.193.882 visitas únicas, um aumento de $13,0 \%$ em relação a 2012. A maioria dos utilizadores $(47,0 \%)$ são de nacionalidade espanhola, seguidos de britânicos (12,0\%) e alemães (10,0\%). Outra das vertentes é a comercialização online na Web oficial de produtos, serviços e experiências. Fez-se um esforço de melhora das narrativas turísticas, fotografias e vídeos, textos e funções, incluindo a reserva de experiências diretamente no website.

Para promover a visibilidade da página Web oficial nos diferentes motores de pesquisa e portais de agregação de conteúdo realizaram-se ações de marketing de tipo SEO - Search Engine Optimization, isto é, de otimização da indexação do website nos motores de pesquisa e aperfeiçoamento do seu posicionamento (campanhas de intercâmbio de links, otimização técnica da página, participação em websites colaboradores para aumento da popularidade); ações de tipo SEM - Search Engine Marketing- campanhas de pago por clique; publicidade em 
páginas de terceiros com importância estratégica e com grande audiência, por exemplo banners em websites da indústria turística como agências de viagem ou operadores turísticos, linhas aéreas, blogues de viagem; contratação de campanhas em páginas Web especializadas com grande impacto nos segmentos e mercados emissores (por exemplo blogues de golfe, etc.).

Para aumentar a visibilidade do destino, o Turismo de Tenerife dinamizou a imagem nas redes sociais próprias e em páginas geridas por outros atores turísticos (estabelecimentos turísticos, restauração, fornecedores de experiências, etc.). Para este objetivo contribuiu igualmente o desenvolvimento de projetos de literacia em redes sociais, como o projeto de "Tenerife Stream".

O Turismo de Tenerife realizou também a contratação de campanhas promocionais em redes sociais e viagens de familiarização com os prescritores digitais mais influentesbloggers e jornalistas online especializados em viagens (ver Anexo 1). Depois da análise das diferentes redes sociais, em concreto o TripAdvisor, Facebook, Twitter, Youtube, Flickr e Wikipedia, o Turismo de Tenerife criou um modelo de presença online para o destino que foi vertido num manual de aplicação e cujos objetivos principais são aumentar o número de seguidores do Facebook e Instagram corporativos e dos restantes atores turísticos; criar conteúdos e posts mais personalizados com narrativas variadas sobre o destino; chegar a ter uma interação direta com os utilizadores; e a criação de canais promocionais online em diferentes idiomas.

\section{Conclusão}

Pretendíamos, com este estudo, apresentar uma reflexão sobre a estratégia de comunicação de um destino turístico de êxito e identificar as suas best practices, de forma a que pudessem ser facilmente extrapoláveis a outros destinos turísticos, nomeadamente para Portugal.

Devido ao paradigma de mudança em comunicação turística, o Turismo de Tenerife passou para segundo plano o realce das caraterísticas funcionais de um destino de "Sol e Praia", apostando numa comunicação centrada num discurso emotivo no qual se destacam as experiências e dando preferência às ações desenvolvidas em canais online.

Encontramos uma visão estratégica orientada para a excelência e uma estrutura de gestão inspirada num modelo turístico holístico, que entende o destino como um todo global, que necessita de respostas integrais desde a comunicação à revitalização, da atenção ao cliente passando pelas questões da acessibilidade, conectividade, desenvolvimento tecnológico, inovação e aposta por novas áreas do conhecimento.

A estratégia de comunicação turística de Tenerife não se resume apenas ao uso de narrativas turísticas centradas nas pessoas e nas experiências, mas também promove uma estratégia de negócio holística que incita a diversidade da oferta de produtos e experiências memoráveis para turistas e população residente. Com esse fim, renovou-se o manual de marca e os slogans para transmitir sensações e experiências. Para destacar a variedade de produtos e experiências turísticas, o Turismo de Tenerife adequou as mensagens comunicacionais às novas estratégias de posicionamento de imagem do destino. Esta organização optou pela diferenciação e personalização dos conteúdos promocionais e comunicacionais de acordo com os segmentos estratégicos, adequando conteúdos, suportes e canais promocionais às tendências do consumidor e às novas tecnologias. 
Para dar resposta ao paradigma comunicacional 2.0 (ou 3.0 em certos casos), a estratégia em comunicação turística incorporou como plataformas prioritárias, a Internet, as redes sociais e blogues de viagem e as aplicações 3.0. O Turismo de Tenerife reconhece a crescente influência das novas tecnologias no processo de comunicação turística e que a Internet é atualmente o canal principal de informação, com maior relevância que as tradicionais fontes de informação: imprensa, rádio e televisão, postos de informação turística, feiras de turismo, entre outras.

A segunda fonte de informação mais referida nos questionários foi a comunicação interpessoal, concretamente, as recomendações de bloggers, amigos e familiares e de outros utilizadores através das redes sociais. Ciente da importância da comunicação interpessoal online, em especial da influência das recomendações realizadas por outros turistas, o Turismo de Tenerife realiza ações para melhorar a visibilidade do destino na sociedade em rede. Esta organização tem em ação um plano de relacionamento online de forma a interatuar com os turistas durante os três momentos chave do processo de consumo: antes da viagem (Web e redes sociais), durante a viagem (ações em terminais móveis, uso de aplicações informativas sobre o destino potenciadas por tecnologia 3.0 como realidade aumentada, códigos $Q R$ e sistemas de georreferenciação) e após a viagem (estimulando a recomendação positiva em redes sociais, o reavivar das experiências e a vontade de voltar, através de ações de emailmarketing e concursos em redes sociais).

A estratégia de promoção e gestão de reputação nas redes sociais incluiu ações que potenciem o turista como ator-prescritor voluntário do destino em tempo real. Contemplaram-se as diferentes plataformas de comunicação online, diferenciando a emissão de mensagens em forma e conteúdo segundo os dispositivos de receção final (fixos e móveis). Outro objetivo é melhorar o posicionamento da Web oficial como o portal de referência em informação turística sobre o destino.

A utilização de imagens atraentes nos discursos de comunicação turística aparece como uma estratégia de persuasão e sedução. As composições estéticas sedutoras presentes nas peças de comunicação analisadas têm por objetivo enaltecer os argumentos turísticos diferenciadores, as qualidades e experiências que o destino tem para oferecer, estimulando o desejo de consumo, de descoberta e de atração.

Em suma, a comunicação turística não deixa de ser uma comunicação persuasiva, e afirma-se pela eficácia com que se cumprem os seus objetivos. E o êxito do modelo de comunicação turística de Tenerife está atestado, não apenas pelos bons resultados de ocupação (os melhores em toda a Europa), mas também pelo sentimento positivo dos diferentes mercados emissores em relação à marca. A comunicação tem hoje um papel estratégico ao tentar influenciar e persuadir o comportamento do consumidor turístico num contexto multicanal offline e online, simétrico e multidirecional. A comunicação turística promove o entendimento entre os homens e mulheres de diferentes culturas, engendra e modela novas formas de sociabilidade. Por isso é tão importante este processo da revolução 2.0 a caminho da 3.0, no qual a comunicação turística deixa de ser o exclusivo de alguns, dos gestores de destinos, dos fazedores de marketing, das vendas, da publicidade, da política ou dos media e passa, através da Internet, em especial das redes sociais e das aplicações inteligentes, a integrar a competência argumentativa dos seus próprios destinatários. 


\section{Referências}

Anderson, P., Hepworth, M., Lecturer, S., Kelly, B., Manager, R. M. \& Phipps, L. (2007). What is Web 2.0? Ideas, technologies and implications for education. Bristol: JISC Technology and Standards Watch.

Bastian, H., Dreyer, A. \& Gross, S. (2009). Tourismus 3.0: Fakten und perspektiven (Schriftenreihe Dienstleistungsmanagement: Tourismus, Sport, Kultur). Hamburgo: ITD-Verlag.

Buhalis, D. (2003). E-Tourism: Information technology for strategic tourism management. London: Pearson Education Limited.

Dunn, D. (2015). Those people were a kind of solution: Post-tourists and grand narratives. In T. V. Singh, (Eds.), Challenges in tourism research (pp.27-33). Bristol: Channel View Publications.

Fernández, L. A. H. (2012). Historia viva de la Internet. Barcelona: Editorial UOC.

Fotis, J., Buhalis, D. \& Rossides, N. (2012). Social media use and impact during the holiday travel planning process. In Fuchs, M., Ricci, F. and Cantoni, L. (Eds.). Information and Communication Technologies in Tourism 2012, 13-24. Vienna, Austria: Springer-Verlag.

Hays, S., Page, S. J. \& Buhalis, D. (2012). Social media as a destination marketing tool: Its use by national tourism organizations. Current Issues in Tourism, 16(3), 211-239. doi.org/10.1080/13683500.2012.662215

Horsle, P.B. (2005). Strategical communication as a method. Comunicação e Sociedade, 8, 19-37.

Jandt, F. (2010). An introduction to intercultural communication: Identities in a global community. Los Angeles: Sage.

Kietzmann, J. H., Hermkens, K., McCarthy, I. A. \& Silvestre, B. S. (2011). Social media? Get serious! Understanding the functional building blocks of social media. Business Horizons, 54(3), 241251. doi: 10.1016/j.bushor.2011.01.005

Kotler, P., Kartajaya, H. \& Setiawan, I. (2010). Marketing 3.0: From products to customers to the human spirit.New Jersey: John Wiley \& Sons.

Lalicic, L. \& Dickinger, A. (2017). Tourist-driven innovations in social media: An opportunity for tourism organizations. In M. Sigala, e U. Gretzel, (Eds.), Advances in social media for travel, tourism and hospitality. New perspectives, practice and cases (pp. 59-71). Abingdon: Routledge.

Miguéns, J., Baggio, R. \& Costa C. (2008). Social media and tourism destinations: TripAdvisor case study. Advances in Tourism Research, 26(28), 1-6.

Ribeiro, F. V. M. (2013). O spin doctoring em Portugal: Estudo sobre as fontes profissionais de informação que operam na Assembleia da República (Tese de doutoramento não publicada). Universidade do Minho, Braga.

Schmitt, B. (2010). Experience marketing: Concepts, frameworks and consumer insights, 5(2), 55-112. doi.org/10.1561/1700000027

Sharpley, R. \& Stone, P.R. (2011). Tourist experience: Contemporary perspectives. Abingdon: Routledge.

Sigala, M. \& Gretzel, U. (2018). Advances in social media for travel, tourism and hospitality. New perspectives, practice and cases. Abingdon: Routledge.

Tocquer, G. \& Zins, M. (1999). Marketing do turismo. Lisboa: Instituto Piaget.

Tratt, N. (2014). Leveraging influencers to tell an authentic brand story and drive return on investment: Case study of Travel Alberta and Expedia Media Solutions. Journal of Digital \& Social Media Marketing, 2(2), 125-130.

Tseng, C., Wu, B., Morrison, A., Zhang, J. \& Chen, Y. C. (2015). Travel blogs on China as a destination image formation agent: A qualitative analysis using Leximancer. Tourism Management, 46, 347-358. doi.org/10.1016/j.tourman.2014.07.012

Toffler, A. \& Toffler, H. (2006). Revolutionary wealth. New York: Alfred Knopf.

Turismo de Tenerife (2012). Los visitantes de Tenerife 2012. Tenerife: Publicaciones de Investigación de Turismo de Tenerife.

Turismo de Tenerife (2013a). Informe de situación turística de Tenerife 2013. Tenerife: Publicaciones de Investigación de Turismo de Tenerife.

Turismo de Tenerife (2013b). Presentación situación turística y perfil 2013. Tenerife: Publicaciones de Investigación de Turismo de Tenerife.

Turismo de Tenerife (2014). Informe situación turística em Tenerife. Tenerife: Publicaciones de Investigación de Turismo de Tenerife.

Urry, J. (2001). O olhar do turista. Lazer e viagens nas sociedades contemporâneas. (Trad. C.E.M. Moura). São Paulo: Studio Nobel / SESC. 
Urry, J. \& Larsen, J. (2011). The tourist gaze 3.0. London: Sage Publications.

Uzunoglu, E. \& Misci Kip, S. (2014). Brand communication through digital influencers: Leveraging blogger engagement. International Journal of Information Management, 34(5), 592-602. doi.org/10.1016/j.ijinfomgt.2014.04.007

Wichels, S. (2014a). A experiência sensorial na comunicação turística. Revista da Faculdade de Letras da Universidade de Coimbra 11, 475 - 494. doi.org/10.14195/0870-4112_11_20

Wichels, S. (2014b). Nuevos desafíos en relaciones públicas 2.0: La creciente influencia de las plataformas de online review en turismo. Revista Internacional de Relaciones Públicas, 7 (IV), 197-216. doi.org/10.5783/RIRP-7-2014-12-197-216

Wong E., Law R. \& Li, G. (2017). Reviewing geotagging research in tourism. In Information and Communication Technologies in Tourism (pp. 43-58). Cham: Springer. doi.org/10.1007/978-3319-51168-9_4

Yin, R. K. (2001). Estudo de caso: Planejamento e métodos. (Trad. Daniel Grassi). Porto Alegre: Bookman.

Zarantonello, L., Jedidi, K. \& Schmitt, B. H. (2013). Functional and experiential routes to persuasion: An analysis of advertising in emerging versus developed markets. International Journal of Research in Marketing, 30(1), 46-56. doi.org/10.1016/j.ijresmar.2012.09.001

SUSANA WICHELS é mestre em Comunicação e Jornalismo pela Faculdade de Letras da Universidade de Coimbra, Portugal (2014) e em Gestão de Empresas Turísticas pela Faculdade de Ciências Empresariais da Universidade de La Laguna, Espanha (2003). Cursa atualmente o Mestrado em Seguros e Finanças pela UDIMA, Espanha, e encontra-se na fase final do Doutoramento em Ciências da Comunicação e Novas Tecnologias na Faculdade de Letras da Universidade de Coimbra. Wichels reside desde 2002 em Espanha, onde tem desenvolvido uma carreira como responsável de marketing e comunicação digital em diversas empresas no setor hoteleiro e financeiro (mais de 15 anos de experiência). Departamento de Comunicação e Jornalismo, Faculdade de Letras, Universidade de Coimbra, Largo da Porta Férrea, 3000-370 Coimbra.

Submetido em 30 setembro 2017

Aceite em 14 abril 2018 


\section{Anexos}

Anexo 1. Resumo de ações de comunicação realizadas em 2013 pela marca Tenerife Select

\begin{tabular}{|c|c|}
\hline TENERIFE SELECT & \\
\hline ACClON & MERCADO \\
\hline ROAD SHOW THOMAS COOK & ALEMANIA \\
\hline BLOG TRIP TRAVELETTES & ALEMANIA \\
\hline REVISTA PATIENTEN JOURNAL & ALEMANIA \\
\hline REPORTAUE DINERS CLUB & ALEMANIA \\
\hline CAMAPAÑA COCOONING TIME & BENELUX \\
\hline JORNADAS COMERCIALIZACIÓN EXCLUSIVE SPAIN & BENELUX \\
\hline CAMPAÑA CON TTOO SOVEREIGN & REINO UNIDO \\
\hline FAM TRIP TENERIFE SELECT \& BRITISH AIRWAYS-TTOO LUJO I & REINO UNIDO \\
\hline WORKSHOP PRESTIGE HOLIDAYS & REINO UNIDO \\
\hline COLABORACIÓN FAM TRIP BRITISH AIRWAYS HOLIDAYS & REINO UNIDO \\
\hline COLABORACIÓN FAM TRIP AZURE COLLECTION & REINO UNIDO \\
\hline PRESS TRIP THE SUNDAY TIMES & REINO UNIDO \\
\hline JORNADAS DE BRIGHT-ASHFORD CON PROMOTUR & REINO UNIDO \\
\hline CAMPAÑA DE PUBLICIDAD EN BRITISH AIRWAYS TV & REINO UNIDO \\
\hline VIDEO TENERIFE SELECT EN TRAVELGURU CAMPAÑA BATV & REINO UNIDO \\
\hline FAM TRIP TENERIFE SELECT \& BRITISH AIRWAYS-TTOO LUJO II & REINO UNIDO \\
\hline REPORTAJE EN EXCLUSIVE MAGAZINE & NACIONAL \\
\hline REPORAJE EN CONDE NAST TRAVELER & NACIONAL \\
\hline REPORTAJE Y BANNER EN ELLLE.COM & NACIONAL \\
\hline REPORTAE YO DONA-CAMPAÑA BARCELO & NACIONAL \\
\hline PIEZA TURISMO DE LUJO PARA ANTENA 3 & NACIONAL \\
\hline REPORTAJE EN HOSTELTUR TURISMO MEDICO & NACIONAL \\
\hline REPORTAJE EN HOLA.COM & NACIONAL \\
\hline WORKSHOP EN MUTUA MADRID OPEN 2013 & NACIONAL \\
\hline FAM TRIP INTERNATIONAL BUSINESS CONSULTING CHINA & INTERNACIONAL \\
\hline FAM TRIP THE WORLD OF ELAN-LA INDIA & INTERNACIONAL \\
\hline FERIA INTERNATIONAL LUXURY TRAVEL MARKET CANNES & FRANCIA \\
\hline WORKSHOP UPMARKET \& MICE PARIS & FRANCIA \\
\hline ARTICULO EN REVISTA CHALLENGES & FRANCIA \\
\hline PRESS TRIP TENERIFE SELECT-FRANCIA & FRANCIA \\
\hline GUIA DE VIAJES AFISHA MIR & RUSIA \\
\hline FERIA LUXURY TRAVEL MART MOSCU & RUSIA \\
\hline PRESS TRIP TENERIFE SELECT-RUSIA & RUSIA \\
\hline REPORTAJE TTG LUXURY & RUSIA \\
\hline COLABORACIÓN FAM TRIP AEROFLOT & RUSIA \\
\hline FAM TRIP AVIAREPS & RUSIA \\
\hline CREACIÓN PRODUCTO TURISMO MÉDICO & INTERNACIONAL \\
\hline CAMPAÑA EN REDES SOCIALES & INTERNACIONAL \\
\hline
\end{tabular}

Fonte: Turismo de Tenerife (2013b). 
Anexo 2. Levantamento fotográfico dos Outdoors realizados em visita de campo em setembro de 2013
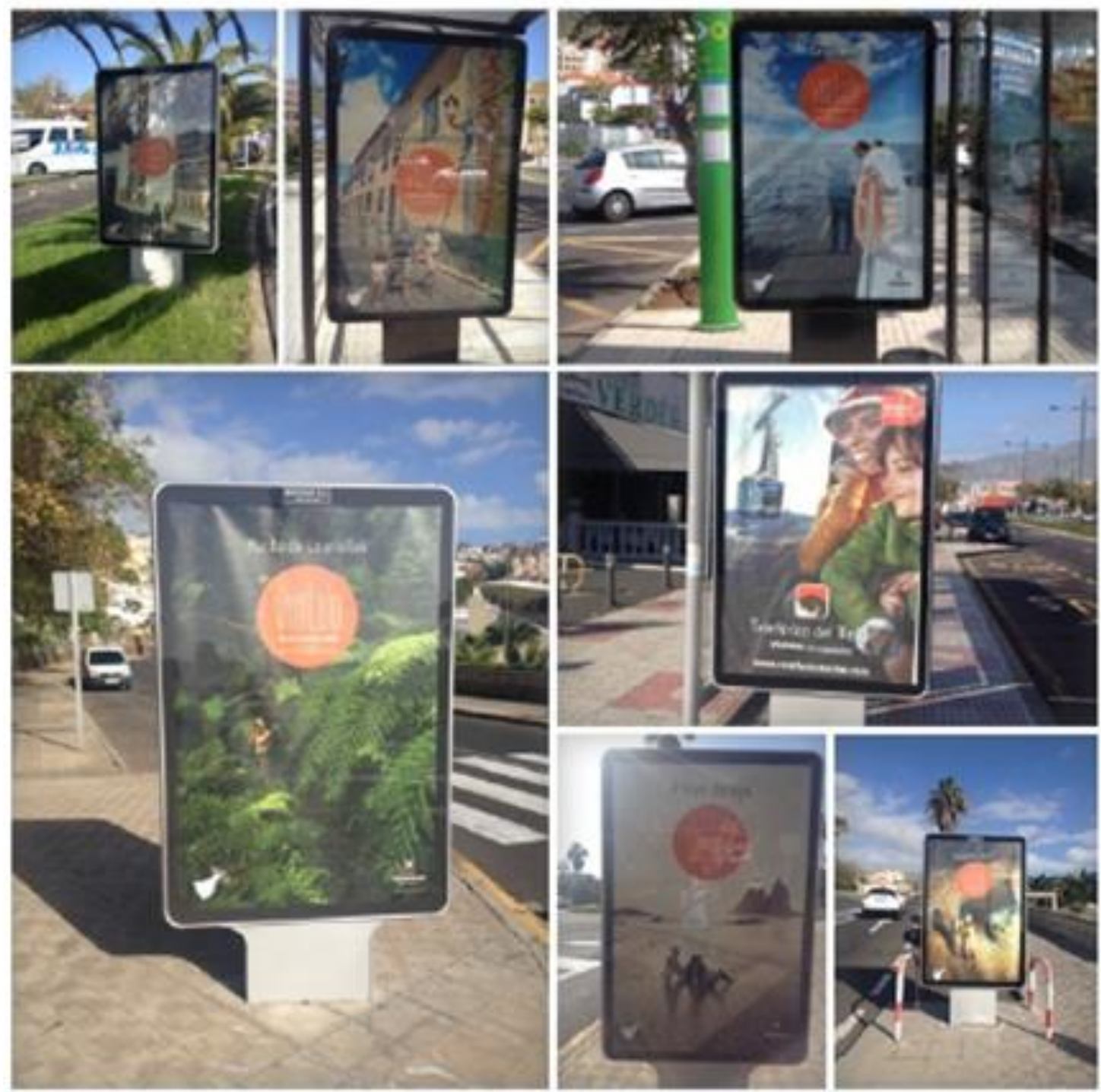
Anexo 3. Algumas peças de comunicação da campanha "No Winter Blues"

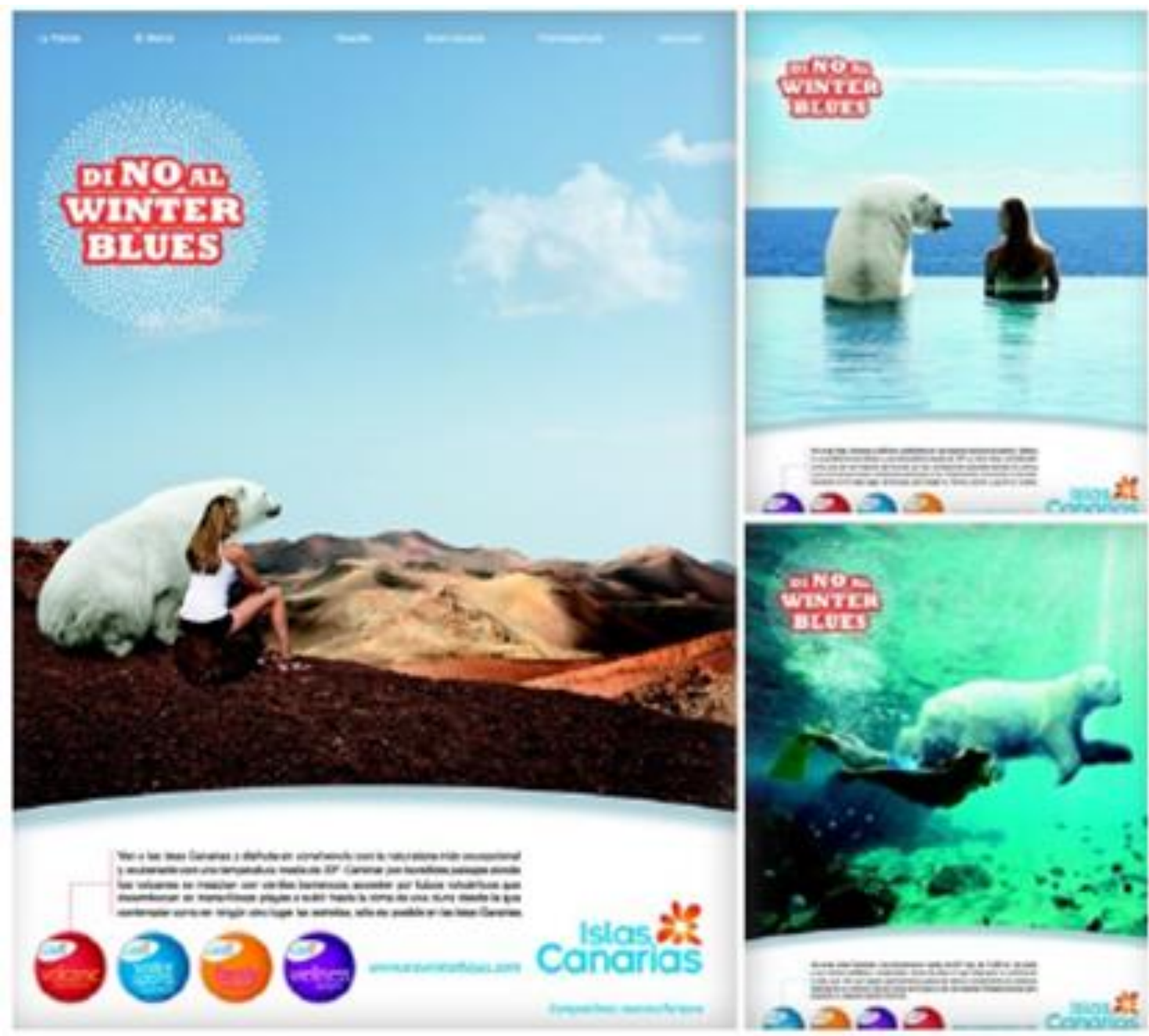

Fonte: Turismo de Canarias (http://www.turismodecanarias.com). 


\section{Anexo 4. Algumas peças de comunicação da campanha "Tenerife Amable"}

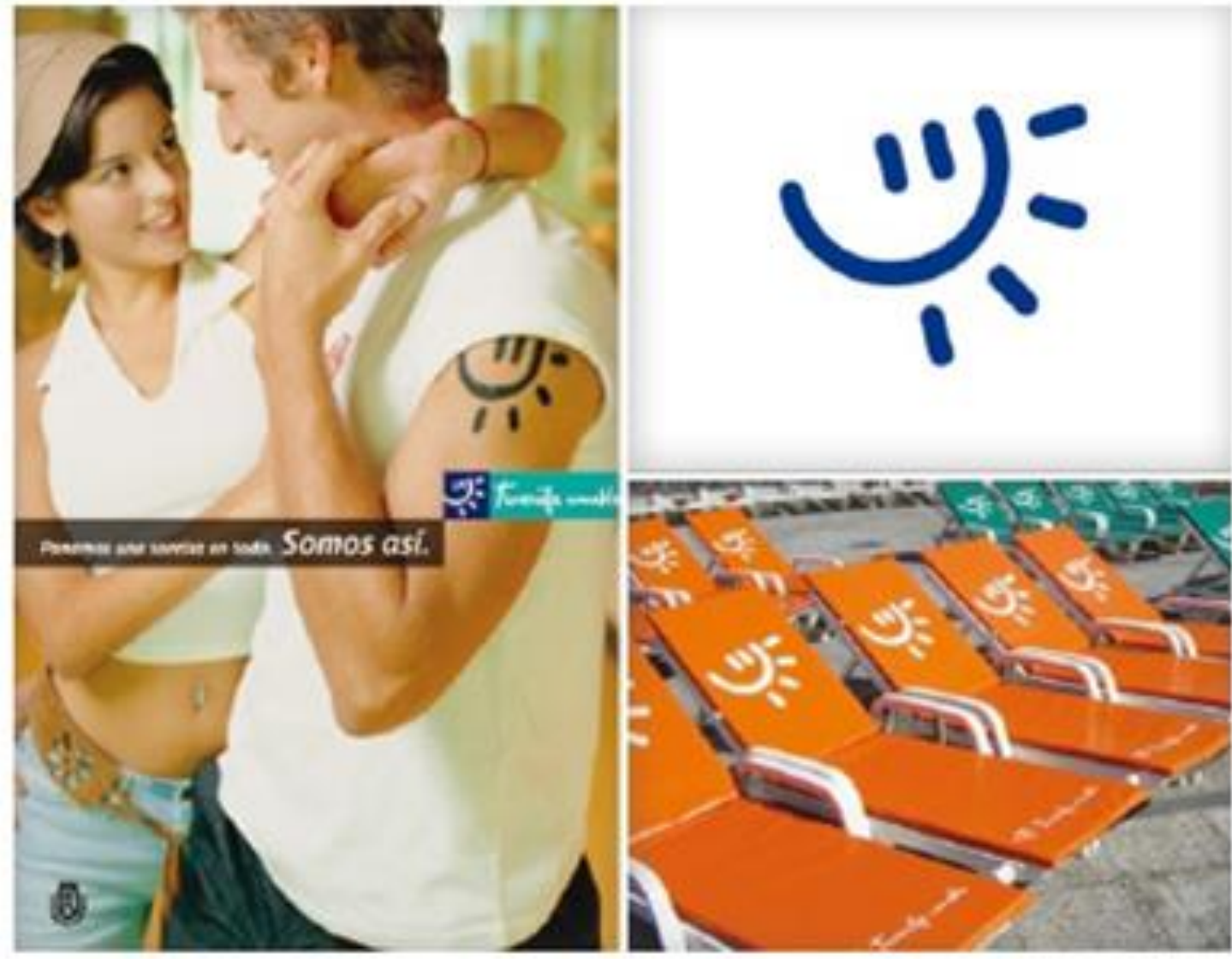

Fonte: Turismo de Tenerife (http://valladaresdc.com/portfolio/diseno-publicitario-tenerife-amable/). 